\title{
Key knowledge management strategies implemented in the Kingdom of Saudi Arabia construction industry: An empirical study
}

\author{
Suresh Renukappa* \\ Faculty of Science and Engineering, \\ University of Wolverhampton, \\ Wolverhampton WV1 1LY, UK \\ Email: suresh.renukappa@wlv.ac.uk \\ *Corresponding author \\ Hanouf Alosaimi \\ Faculty of Science and Engineering, \\ University of Wolverhampton, \\ Wolverhampton WV1 1LY, UK \\ Email: H.Alosaimi@wlv.ac.uk

\section{Subashini Suresh} \\ Faculty of Science and Engineering, \\ University of Wolverhampton, \\ Wolverhampton WV1 1LY, UK \\ Email: S.Subashini@wlv.ac.uk
}

\begin{abstract}
The Kingdom of Saudi Arabia (KSA) construction sector is an important industry and contributes approximately $20 \%$ of the gross domestic product (GDP). However, uncertainty, complexity, sustainability and Saudi Arabia National Policy Plan 2030 are among the most important features of the current construction business environment in the KSA. Therefore, for the KSA construction organisations, the creation of economic value by addressing the above issues now increasingly poses real profound strategic challenges. This paper focuses on key knowledge management (KM) strategies that the KSA construction organisations implemented en route to organisational competitiveness. The findings are in the main, based on semi-structured interviews with 46 professionals from 30 construction organisations. The data analysis revealed that, the key initiatives implemented broadly under the umbrella of KM are knowledge sharing initiatives, knowledge capturing initiatives and knowledge mapping initiatives. The scarcity of knowledge and expertise is, and will continue to be, a huge challenge for many construction organisations in the KSA.
\end{abstract}

Keywords: construction industry; Kingdom of Saudi Arabia; knowledge management; tacit knowledge.

Biographical notes: Suresh Renukappa currently serves as a Senior Lecturer in the Faculty of Science and Engineering at the University of Wolverhampton. He holds a PhD in managing change and knowledge associated with sustainability initiatives for improved competitiveness. He has over 20 years of research, consultancy, project management and teaching experience in a wide range of business and management areas across industrial sectors in both developed and emerging economies. His research interests cover, but not limited to, sustainability strategies for competitive advantage; carbon reduction strategies; corporate social responsibility; smart cities development; leading change towards 
sustainability; knowledge management; public private partnerships; cloud computing; infrastructure asset management; and sustainable infrastructure investment and development. He has successfully executed more than 30 large projects and authored over 80 papers which have been published in journals, book chapters and conference proceedings.

Hanouf Alosaimi is a $\mathrm{PhD}$ researcher in the Faculty of Science and Engineering at the University of Wolverhampton. Her research investigates the current level of understanding and implementation of knowledge management practices in the Kingdom of Saudi Arabia construction industry for competitive advantage. She holds Master of Business in Human Resources Management from the Wolverhampton Business School, UK. Hanouf graduated from King Saud University of Saudi Arabia with a Bachelor of Social Work. She received scholarship from Saudi Arabian Cultural Bureau to do her MBA and PhD degrees. She has published two conference papers in the area of knowledge management. Her research interests include: human resources management, knowledge management, women in Saudi Arabian construction industry and competitiveness.

Subashini Suresh has over 19 years of experience in research, teaching and practice in the area of Project Management and has worked in the area of Architecture, Engineering and Construction (AEC) sector in UK, USA, UAE, Nigeria, Ghana, Italy, Netherlands and India. Currently, she is a Reader of Construction Project Management at the School of Architecture and Built Environment, University of Wolverhampton. She holds a $\mathrm{PhD}$ in knowledge management. She received Rewarding Excellence Award for Innovation in Teaching and also for Blended Learning Tutor. She has published over 150 academic publications, which include 27 journal papers, 95 conference papers, four articles, eight book chapters, 15 reports and three books. Her key areas of interest are as follows: construction project management, knowledge management, building information modelling, health and safety, sustainability/green construction, emerging technologies, quality management, leadership in change management initiatives, organisational competitiveness, business process improvement, lean construction, risk management, and Six Sigma leadership.

\section{Introduction}

The Kingdom of Saudi Arabian (KSA) construction is worth USD 25.3 billion and contributes approximately $20 \%$ of the Saudi Arabia GDP and continues to be, the most significant economic activity outside the oil sector (RnR Market Research, 2014, Timetric, 2014). This is particularly important in the Saudi Arabian construction sector as the Saudi Government is making huge investments in its attempt to move towards a knowledge-based society as highlighted in the vision 2030 of the Saudi Arabian National Policy Plan (Al Hussain et al., 2012). Alotaibi et al. (2013) state that large number of mega construction projects being carried out in the Saudi private and public sectors due to rapid economic growth of the KSA. However, uncertainty, complexity, sustainability, climate change, and Saudi Vision 2030 are among the most important features of the current construction business environment in the KSA. There is also a shortage of skilled, experienced local engineers in Saudi Arabia, which is hampering the growth and development of the local construction sector. The strict Suadization measures imposed across the industry resulted in large scale and acute shortage of skilled labour to meet the needs of the growing construction, causing delays in projects for which contracts had been awarded (Ventures, 2015). Therefore, for the KSA construction organisations, the creation of economic value by addressing the above 
issues now increasingly poses real profound strategic challenges. As organisations try to meet these complex challenges, they need to be innovative.

It is widely recognised that knowledge is an essential strategic resource for an organisation to retain a sustainable competitive advantage. Therefore, managing knowledge has become significant for today's organisations to meet changes and challenges. Specifically with respect to the construction industry, Yu et al., (2013) highlighted the complexity associated with the knowledge-intensive environments of the construction industry where cumulative identity of experiences and knowledge daily differ across engineers, projects and companies. Construction project activities are knowledge-intensive activities which place construction organisations in the position to find ways to manage their knowledge more efficiently and effectively (Rezgui et al., 2010). Thus studies have reported that the need for effective knowledge management (KM) in the construction industry by reusing and sharing knowledge to improve quality, reduce time and cost of project completion and ultimately improve competitiveness (Ahmad and An, 2008; Yu et al., 2013).

Khuzaimah and Hassan (2012) pointed out that knowledge must be deliberately and consciously managed in a systematic manner to enable organisations to avoid repetition of costly mistakes, to achieve improved performance and reinvention of wheels. However, the process of managing knowledge in the construction industry is not a simple task and requires thorough planning and preparation. Due to the intrinsic characteristics of the construction industry that is highly fragmented and transient in nature, the success rate of managing project knowledge has been somewhat minimal (Egbu and Robinson, 2005).

Knowledge is a vital resource for construction oriented organisations. In construction projects knowledge is scattered and the pool of knowledge could be lost if there is no proper channel for the knowledge created during the construction phase, for re-use on other projects (Kasimu et al., 2013). The knowledge can be divided in two categories, known such as tacit knowledge and explicit knowledge. Where, the tacit is normally defined as the personal knowledge which is difficult to formalise, written down, explained and described. In contrast of the tacit is the explicit knowledge which is easily to formalise and described, which means is easily transmitted between people (Nonaka, 1994). In the same vein Hariharan (2015) supported this view defining the tacit knowledge is normally managed by experts, due to its difficult nature to document and share with others. In broader perspective, Gerami (2010) also share the same opinion, pointing out that, this type of knowledge is normally in the peoples mind, obtained through their experiences.

Contrasting with the tacit, explicit knowledge is a more formal and could be transferred and managed by words, numbers in different type of sources such as a books, manuals, journals, data bases and others (Steven, et al., 2010). However Suresh, et al., (2017) explained there are different forms of knowledge mentioning them as tacit, explicit, hard, soft, tangible and intangible. But the majorities of authors just recognise the $\mathrm{KM}$ in the two common classifications. Shah et al (2014) established that, the tacit knowledge can be divided in two categories as a cognitive and technical. Where the cognitive is created by working models of the surrounding world, which the mind plays an important role because is who creates and manipulates all the interpretations. The cognitive elements can comprise paradigms, beliefs, and viewpoints which are used by the mind to creates pattern and perceive and define the environment. Nonaka (1994) points out that, a person recognise and interpret the surrounding environment through the patterns of the cognitive knowledge and the technical knowledge is based on of the know-how, abilities and techniques apply to a specific situation. 
McEvily and Chakravarthy (2002) acknowledge that the tacit knowledge it is specific and complex, due to once is developed inside the organisation start to generate long lasting advantage because this type of knowledge is too difficult to imitate. The organisation can expand their knowledge base through the application of existing knowledge in the company, along with the new one (Szulanski, 2003), allowing the organisation absorbs the internal and external knowledge and mix them with the pre-acquired knowledge, and creates new one (Cohen and Levinthal, 1990). Even the explicit knowledge can be involved. This can be combined with the internal knowledge which may result in new and exclusive knowledge (Zack, 2002). Therefore, KM can be seen as a tool in order to enhance organisational performance with many academic and practitioners advocating the construction organisational benefits of KM including delivery of projects with quality, shorter design and production times, customer and staff satisfaction and market leadership (Carrillo and Chinowsky, 2006; Suresh et al., 2017). In addition, Teerajetgul et al., (2009) emphasised that $\mathrm{KM}$ is in fact the formalisation of the admittance in the direction of experience, knowledge and expertise with the aim of creating new capacities, facilitate better quality performance, promote innovation, as well as improve customer worth. Kasimu (2013) acknowledges when experiences, in other words knowledge and skills are properly shared at the right time then the same problems in the construction project do not necessarily need to be solved constantly.

Hislop (2013) define KM as an umbrella term which refers to any deliberate efforts to manage the knowledge of an organisation's workforce, which can be achieved via a wide range of methods including directly, through the use of particular types of information and communication technology, or more indirectly through the management of social processes, the structuring of organisation in particular ways or via the use of particular culture and people management practices. Alavi and Leidner (2001) defined KM as the systematic process of acquiring, organising and communicating knowledge both tacit and explicit of organisational members so that others may make use of it to be more effective and productive. Within the construction industry context the KM process has been perceived as the combination of a series of activities for identifying, capturing, sharing and using knowledge (Suresh et al., 2017). Indeed, KM strategies can help to avoid the repetition of similar mistakes from previous work and therefore improve work efficiency. In other words, KM strategies can avoid additional effort, reduce the time spent and save money (Kamara et al., 2002).

Considering the prevailing and emerging political and economic conditions in the KSA, the Vision 2030 presents several upcoming opportunities for the growth and development of the country. Such opportunities also highlight the need for inculcating effective KM practices within the KSA construction organisations to enhance the skills, ability and knowledge among the employees to be able to take advantage of the growth opportunities increase their profitability and sustainability (Fakeeh, 2016). In this respect, the Vision 2030 emphasises three pillars, firstly, the position of KSA to be central to the Arabian and the Islamic countries; secondly, determination of the country to emerge as a global investment powerhouse and transform the unique strategic location of the country into an international centre that connects the three continents of Europe, Asia and Africa. The focus in these areas opens numerous opportunities of growth and expansion for the organisations, which can capitalise on such opportunities by harnessing knowledge among the employees (Fakeeh, 2016). Thus, KM is proved to be highly essential for the growth of construction organisations of the KSA (Whittom and Roy, 2009). Although KM has been widely practiced in the western countries, there is a little evidence in the KSA especially in the construction industry. 
Therefore, the aim of this paper to investigate key KM strategies the KSA construction organisations implemented en-route to organisational competitiveness.

For the purpose of this research, KM is defined as "a systematic and integrative process of coordinating the organisation-wide activities of mapping, capturing, and sharing knowledge by individuals and groups in pursuit of the major organisational sustainability goals and objectives”. Various construction organisations in KSA are engaged in the KM strategies for leveraging knowledge within the organisation and across the value chain. For successful KM implementation, it is essential for the KSA construction organisations to establish knowledge networks and develop an effective mechanism for knowledge mapping, capturing, and sharing.

\section{Research Methodology}

The aim of this research is to investigate key KM strategies the KSA construction organisations implemented en-route to organisational competitiveness. In order to achieve this aim, a robust methodology was considered essential. Tutt et al (2012) noted that research methodology in social enquiry refers to far more than the methods adopted and encompasses the rationale and philosophical assumptions that underlie a particular study. These, in turn, influence the actual research methods that are used to investigate a problem and to collect, analyse and interpret data. Therefore, the choice of research methodology is a crucial and difficult step in the research process.

Gable (1994) argued that an explorative qualitative approach is better suited to study a nascent research field and gain valuable initial insights, rather than large scale surveys. Unfortunately, not much is understood about how KSA construction organisations most effectively implement KM initiatives and what leaders do to successfully set and integrate KM strategies and goals. In fact, many KSA construction organisations are struggling to fully implement a KM framework and find that integration of this "new work" into the corporate culture, and the leadership required, to be quite challenging. Therefore, given the complexity of $\mathrm{KM}$ issues and the paucity of comparable research in the KSA, qualitative research methodology was adopted.

Qualitative research, based on an interpretive paradigm, is exploratory by nature, thus enabling researchers to gain information about an area in which little is known (Liamputtong and Ezzy, 2005). According to Bryman and Bell (2015), the qualitative method tends to be concerned with words rather than numbers. The findings of qualitative research are focused acknowledging the qualities of phenomena rather than their mathematical measurement. The qualitative method covers the subject of study holistically. Hyde (2000) noted that qualitative produces a wealth of detailed data on a small sample and the data collection is not restricted to predetermined categories or themes. Therefore, the philosophical underpinning of this study is based on constructivist-interpretive paradigms.

Bernard (2006) noted that data gathering is crucial in research, as the data is meant to contribute to a better understanding of a theoretical framework. Primary data was collected through semi-structured interviews. Indeed, semi-structured interviews were selected, due to flexibility they afford whilst still allowing detailed responses between the interviewer and the interviewee (Smart et al., 2014). To ensure greater dependability and transferability (Creswell, 2014), a total of 46 professionals from 30 KSA construction organisations were interviewed. 
It is imperious that selecting the manner of obtaining data and from whom the data will be acquired be done with sound judgment, especially since no amount of analysis can make up for improperly collected data (Tashakkori and Teddlie, 2010). Therefore, a purposive sampling technique was used in order to achieve representativeness. The purposive sampling technique, also called judgment sampling, is the deliberate choice of a participant due to the qualities the participant possesses. It is typically used in qualitative research to identify and select the information-rich cases for the most proper utilization of available resources (Patton, 2014). This involves identification and selection of individuals or groups of individuals that are proficient and well-informed with a phenomenon of interest (Creswell, 2014). In addition to knowledge and experience, Bernard (2006) noted the importance of availability and willingness to participate, and the ability to communicate experiences and opinions in an articulate, expressive, and reflective manner. The study sample included directors, advisers and managers responsible for KM strategies implementation in their respective organisations.

The interviews took place between the months of July and December 2016 and were recorded with the prior authorisation of respondents in an iPhone handset and supplemented with field notes as appropriate. The format of these interviews was face-to-face. The interviews lasted between 30 and 90 minutes, with later transcription of the entire content of the interviews. The analysis of the interviews was undertaken using Content Analysis. This type of analysis is practical when open-ended questions are used in soliciting information, because it allows for defining content categories through coding. Selecting and defining categories (codes) is analogous to treating open-ended questions as if they were closed-ended in survey research (Singleton and Straits, 2005). Fraenkel and Wallen (2003) noted that content analysis is a study of textual messages of human behaviour in an indirect way. This helps researchers generalise findings, predict the future, understand attitudes, values and cultural patterns of an organisation or an industry or a country.

In the study, coding of the transcribed documents involved open coding of meaning units, that is, words, phrases, sentences, paragraphs, which essentially involved labelling concepts. The emerging concepts were mapped into themes. Threats to validity were minimised through triangulation of data collection methods (interviews, internal and external documents) and verification of the initial thematic codes by participants, where they judged the accuracy of data collected, though not its conclusions. The unit of analysis adopted for this study was the KSA construction industry, and the embedded unit of assessment was the 'individual employee'.

\section{Key KM strategies implemented for competitive advantage in the KSA construction organisations}

In this study, interviewees were asked to list and describe key KM strategies that have been implemented in their organisation through face-to-face interviews. Table 1 shows the three key KM strategies as revealed by those interviewed in this study. Each of these key strategies is discussed in detail below.

Table 1: Implementation of KM strategies for competitive advantage in the KSA construction organisations

\begin{tabular}{|l|l|}
\hline KM strategies implemented & $\begin{array}{l}\text { Percentage of interviewees cited } \\
(\mathbf{N}=\mathbf{4 6})\end{array}$ \\
\hline Sharing knowledge & $85 \%(39 / 46)$ \\
\hline Capturing knowledge & $70 \%(32 / 46)$ \\
\hline Mapping knowledge & $50 \%(23 / 46)$ \\
\hline
\end{tabular}




\subsection{Sharing knowledge}

Knowledge sharing is the voluntary dissemination of acquired skills and experience to the rest of the organisation (Davenport, 1997). Some define internal knowledge sharing as the beliefs or routines for disseminating knowledge and experience across the units of an organisation (Calantone, et al., 2002). The acts of sharing are very important since an individual's knowledge will not have much impact on the organisation unless it is made available to other individuals (Nonaka and Takeuchi, 1995). A lack of knowledge sharing may inhibit or hinder KM efforts (Ipe, 2003). Although knowledge exists at different levels of an organisation, for instance, at the individual, team, and organisation levels, sharing of knowledge at the individual level is critical to an organisation.

In this study, 85\% (39 of the 46) of the interviewees noted that their organisations have implemented knowledge sharing strategies. The key reasons cited by these interviewees include: to share best practices, to share latest policy issues with key employees, and to accelerate and improve the flow of knowledge between key stakeholders (e.g. between procurement team and design team). In this study, most often cited knowledge sharing techniques and technologies include: community of practice, pod casting, face-to-face discussion, mentoring, seminars, bulletin board, company television channels, team briefs, teleconference, forums, telephones, mentoring and shadowing, an organisation's newsletters, leaflets, and websites.

For instance, one of the interviewees noted that:

"Sharing successes and failures stories in meetings and discussions with employees and key stakeholders are often critical to our success. We also use newsletters as a channel to share success stories, how our colleagues or teams have succeeded in reducing waste or delivering higher quality product, or increased customer satisfaction”.

Of the interviewees, 65\% (29 of the 46) of the noted that their organisations have monetary and non-monetary reward system for sharing knowledge; 61\% (28 of the 46) noted that their organisations encouraged experienced employees to share their knowledge with new or less experienced employees; $52 \%$ (24 of the 46) noted that their organisations have a specific training programme for expanding awareness on sharing knowledge; and only $44 \%$ (20 of the 46) noted that their organisations created new job roles and positions (e.g. knowledge transfer officers) for sharing knowledge.

For instance, in this study, one of the interviewees noted that their organisation has established a cash prize in recognition of employees' exemplary sharing of knowledge related to waste reduction initiatives. It is positive incentive for employees to go beyond their regular job responsibility and to become eligible for a cash award of SR250 to SR500. Another interviewee noted that:

"We have different types of monetary reward systems within our company for encouraging and recognising employee performance with respect to knowledge management. However, I believe that there should be a mixture of monetary and nonmonetary rewards”.

Interviewee from the large multinational company noted that:

"We believe in team working and thus allow the rewards on the achievement of team task rather than individuals because if we do so, employees that are less competent 
may feel de-motivated. This allows the employees to be active in sharing the knowledge."

However, many interviewees believe that, monetary benefits are not the only way to encourage knowledge sharing culture. To encourage employees, many organisations in this study, give out special 'knowledge management awards' every month, quarter, or annually to teams or an individual who successfully introduce new KM related processes. Typical nonmonetary rewards include: public recognition through press releases, newsletter which is distributed to key stakeholders such as suppliers, employees, and local communities and letters of thanks and commendation. Another interviewees from the large construction company echoed the same view that:

"I think non-monetary incentives such as recognition and employee appreciation are more rewarding and valued by employees rather than mere monetary rewards. Promotion and job enrichment are the real incentives which motivate employees. Therefore, our organisation tries to promote employees who are encouraging the flow of knowledge rather than restricting it."

However, one of the interviewees noted that: “...There are no specific incentives in our organisation. Employees are highly subjective about their tasks and there is a consistent habit of knowledge sharing within the organization among employees.”

Analysis of the above results suggests that reward system is a critical tool to implement KM strategies in the KSA construction organisations. But the problem with many reward systems and incentives for sharing knowledge is that useful knowledge comes from the lower cadre in the organisation, from people who are not on incentive systems and probably respond much more readily to the feeling that they belong to highly motivated, leading edge, innovative groups of people (Olatokun and Nwafor 2012).

It is evident from the above results that knowledge sharing strategies are well implemented in the KSA construction organisations. It is evident that organisations are increasingly recognising the importance of utilising their knowledge assets. This recognition is manifested by the creation of reward systems, training programmes and appointment of KM specialists to promote knowledge sharing culture in their organisations.

However, $15 \%$ (7 of the 46 ) of the interviewees noted that their organisations do not have knowledge sharing strategies. Some of the key concerns cited by these interviewees include: lack of top management support, employees reluctant to spend time on knowledge sharing, fear of hosting 'knowledge practices' and low awareness and realisation of the value and benefit of possessed knowledge to others. One of the most important issues when working on a KM strategy is to create the right incentives for people to share and apply knowledge (Olatokun and Nwafor, 2012). Whittington, et al., (1999) noted that the focus of change is not only on organisational process and structure, but also organisational culture. This will, in turn, help harness the discretionary effort essential for installing a sustainable enterprises culture and successfully propelling the entire organisation into future. Therefore, it is suggests that cultural change initiatives such as incentive and reward systems for promoting knowledge sharing need to be institutionalised.

According to Nonaka and Takeuchi (1995), information is the "flow of message", and knowledge is created when this flow of messages interacts with the beliefs and commitments of its holders. Also they argued that organisations cannot create knowledge without 
individuals, and unless individual knowledge is shared with other individuals and groups, the knowledge is likely to have limited impact on organisational effectiveness. Skyrme (2001) noted that compensation and recognition for contributing to knowledge sharing efforts is not sufficiently rewarded to individuals by the organisation. If there is inadequate remuneration, KM strategies can potentially fail as people are less likely to contribute to it. Personal reward systems must support the culture of sharing knowledge (Mayo, 1998). To improve this process, it is crucial to reward employees that contribute their expertise and to make sure employees understand the benefits of KM.

The concept of culture is particularly important when attempting to manage organisationwide change (Senge, et al., 2007). Practitioners are increasingly realising that, despite the best-laid plans, organisational change must include not only changing structures and processes, but also changing the organisational culture including reward systems as well. This is also the case of KM strategies deployment in the KSA construction organisations, which demands a cross-functional teamwork, commitment and active participation.

\subsection{Capturing knowledge}

Many construction organisations are now engaging in KM in order to leverage knowledge both within their organisation and externally to their shareholders and customers. Ulrick (1997) suggested that organisations need to be able to capture the tacit knowledge of its employees and to do this effectively; it is argued that management needs to involve and engage employees fully in the activities of the organisation. According to Tan et al. (2010) knowledge capture is to identify and store knowledge and evaluate information captured; knowledge sharing is to exchange and transfer knowledge to an individual or organisation through media; knowledge re-use is to re-apply knowledge stored for innovation and updating knowledge is to archive and refine knowledge in the repository and keep necessary information up to date. Brooking (1996), noted that only $20 \%$ of knowledge available to an organisation is actually used and the remaining $80 \%$ of the employee's knowledge is wasted without effectively capturing it.

In this study, only $70 \%$ (32 of the 46) of the interviewees noted that their organisations have implemented knowledge capturing strategies. The key reasons cited by these interviewees include: to improve sustainable competitive advantage, to reduce economic risks, to reduce re-work, and to reduce new hires learning time. For instance, in this study, one of the interviewees noted that:

"Our organisation has lacked knowledge about the latest fiscal/regulatory measures, consequences of waste, what happened to it and the potential for reducing it. Therefore, there was a strong need for us to know regarding these issues. In an effort to capture waste management related knowledge, we send our key employees to attend waste management training course to gain the necessary skills. I must admit that training programme was very good. After attending the training course, our employee's hands-on training experience served as the primary source of knowledge about waste reduction activities”.

Analysis of the above statement suggests that organisations are capturing from external consultants. Using partnerships or strategic alliances specially to capture knowledge is a fairly common practice among the interviewed organisations in this study. Most often cited strategies used under the umbrella of 'knowledge capture' include: encouraging employees to participate in project teams with external experts (68\%), capturing knowledge from external 
sources (65\%) (e.g. academic institutes, Government organisations), a written knowledge capture policy (60\%), dedication of resources for knowledge capture (50\%), IT infrastructure (45\%), specific training programmes (35\%), and reward systems to promote knowledge capture strategies (30\%).

Tan et al. (2007) deduces that knowledge capture encompasses three sub-processes. Firstly and foremost, the identification and location of knowledge: concern with the discovering of the natures of knowledge to be managed and the location where such knowledge is situated for learning (Markus, 2001). Secondly, representation and storage of knowledge: meaning indexing, organising and structuring knowledge into exact knowledge areas and authority in the standards (Carrillo and Chinowsky, 2006). Finally, validation of knowledge: to ensure the credibility of knowledge captured and proper storage, with all relevant related facts and in the right format (Kasimu et al., 2013). Dalkir (2005) classified KM technologies according to the following schemes: (a) communication, (b) collaboration, (c) content creation, (d) content management, (e) adaptation, (f) elearning, (g) personal tools, (h) artificial intelligence, and (i) networking. The two important techniques used in the capture of tacit knowledge are content creation and content management using artificial intelligence tools such as decision support systems and expert systems. In this study, most often cited knowledge capturing techniques and technologies include: capturing best practices through interviewing "experts", intranet, learning histories, exit interviews, conducting surveys, after-action-review, real time audio and video recording and minutes of meetings.

In this study, 30\% (14 of the 46) of the interviewees noted that their organisations do not have any strategies to capture knowledge. Some of the concerns cited by these interviewees include: difficulty to capture tacit knowledge, too expensive, difficulty to capture knowledge from external stakeholder, lack of awareness, and lack of knowledge capture tools. Noordin et al. (2012) stressed that failure to capture the knowledge and experiences during the construction phase will result in a great loss to not only the organisation, but represent unnecessary wastages of assets. Indeed, Kasimu et al. (2013) expressed that knowledge across a project is key, in order to transfer knowledge from a current project to future developments. In other words, allows individuals to use existing proven knowledge to solve issues as a substitute of generating new knowledge, which can take up vast amounts of time and resources (Fernie et al., 2003). Thus by, this has shown the need for the development of appropriate strategy for capturing knowledge of construction projects by using technology, techniques, concept and tools. Furthermore, Kasimu et al. (2013) points out that capturing knowledge will help to prevent the loss of critical knowledge due to retirement, downsizing and outsourcing and discards the experts and professionals at the expiration of the project.

However, this study results suggest that, the level of implementation of knowledge capturing strategies is moderate. The results are not surprising because Suresh and Egbu (2012) revealed that the level of implementation of knowledge capture initiatives is still in their infancy in the construction sector. The construction industry is characterised by a wealth of experiential knowledge, yet senior staff retire or leave organisations regularly, potentially taking tacit knowledge and a potential source of competitive advantage with them. Capturing key lessons learned by others as well as good work practices helps to prevent firms from repeating errors while allowing new project teams to build on the work of their predecessors (Dixon, 2000). Therefore, the KSA construction organisations should decide how best to cope with this problem such that as much knowledge as possible is retained within organisational boundaries. 


\subsection{Mapping knowledge}

In this study, only $50 \%$ (23 of the 46 ) of the interviewees noted that their organisations have implemented strategies related to mapping knowledge. Some of the knowledge mapping tools that are most commonly used include: corporate yellow pages, expertise database, hardtagging experts, mind map, business process map and topic maps. The key reasons cited by the interviewees for mapping knowledge include: to improve the flow of knowledge, to identify internal knowledge assets, and to improve accessibility to knowledge. For instance, one of the interviewees noted that:

"Recently, we have modified our company webpage and included a section on 'Health and Safety' (H\&S). Our web team developed and included a sitemap of valuable 'know-how' and 'how to do' on H\&S. This section includes: quarterly electronic newsletters, annual H\&S reports, key contacts related to H\&S, emerging $\mathrm{H} \& \mathrm{~S}$ issues, experts' opinions and success stories related to $\mathrm{H} \& \mathrm{~S}$ in our organisation”.

The aforementioned statement reveals that, organisations are mapping knowledge. Knowledge mapping aimed at the external stakeholders such as communities is most relevant when it comes to visualising and presenting organisation $\mathrm{H} \& \mathrm{~S}$ performance. This can be a form of marketing where the purpose is to attract positive attention, and in the extension some kind of pay-off, new clients/customer contacts, invitations or recognition. The company homepage is an obvious technology for this type of communication. The benefits of using maps in this way improve relationships with the external stakeholder as well as internal staff and a sense of common commitment towards H\&S.

The most often cited strategies implemented for mapping knowledge include: identification of internal and external knowledge sources (45\%), conducting knowledge audit (40\%), dedication of time for mapping knowledge (30\%), encouraging employees to participate in mapping process (25\%), project teams with external mapping experts (23\%), information and communication technologies (ICT) infrastructure (20\%), specific training programme(s) (17\%), and reward system(s) to promote knowledge mapping initiatives (11\%). Overall this study results suggest that knowledge mapping strategies are less implemented in the construction and the NPOs sector. This could be due to the current KM literature has only a few stories to illustrate the potential of such knowledge maps (Eppler, 2003). However, with the rapid development of ICT it is predicted that they may soon become a standard element in organisations' knowledge management strategy.

Significantly, $50 \%$ (23 of the 46) of the interviewees noted that their organisations do not have any strategies for mapping knowledge. Some of the key reasons cited by these interviewees include: lack of knowledge mapping awareness, lack of infrastructure, difficult to map stakeholder's knowledge, and difficult to map tacit knowledge. Knowledge mapping confers benefits such as improved ability to locate knowledge in processes, people, repositories and context; and improved awareness of islands of expertise and evaluation of intellectual and intangible assets, improved decision making and problem solving by providing applicable information, and effective knowledge sharing associated with knowledge exploitation in organisations (Davenport and Prusak, 1998; Eppler, 2003). Conducting 'knowledge auditing' would show how organisation currently creates new knowledge, stores, access, use and share the knowledge that they need to do their jobs. According to Burnett, et al., (2004) a successful audit should effectively reflect the 
organisation knowledge assets and how it flows. It also shows key internal and external sources of knowledge that organisations are using for solving day-to-day business problems.

\section{Conclusion}

Knowledge is an organisations most critical asset and a source of lasting competitive advantage. The construction industry is one of the critical industries that operates in an information-rich environment, which relies heavily on knowledge as one of the strategic resources to ensure the tasks associated with the domain can be performed effectively and efficiently by the project team members. Knowledge has now become widely recognised and accepted as a valuable organisational resource in the KSA construction business. As revealed by the study, the three key KM strategies have been used in the KSA construction organisations at different levels of implementation. They are: sharing, capturing, and mapping knowledge. This study results suggests that the extent of implementation of initiatives related to sharing knowledge is relatively high when compared to capturing and mapping of knowledge. Strategically, tacit knowledge capture is critical when an issue of knowledge continuity arises or due to other concerns with groups and the organisation as a whole. Employee's especially new hires are facing steeper, longer learning curves at the same time that construction organisations are looking for faster revenues and higher productivity. Therefore, there is a great need to develop systems that capture tacit knowledge more effectively in the KSA construction organisations. The KSA construction organisations can benefit from developing a knowledge map or taxonomy that describes the knowledge critical for operations, skills required to perform the tasks, and individuals currently performing these critical tasks. However, it is evident from the current study results that knowledge mapping strategies is under implemented across the KSA construction organisations. This could be due to the fact that mapping of knowledge is in its infancy in the construction organisations. Therefore, there is an urgent need for developing and deploying industry wide knowledge mapping awareness programmes to improve understanding on the concept and benefits of mapping knowledge. The paper concludes that managing knowledge is an integrated and complex process. Taken together, the impact of management commitment and leadership, KM policies, structures, reward systems, training programmes and performance reporting are key factors in successful implementation of KM strategies in the KSA construction organisations.

Given that the research reported in this paper is largely exploratory by nature and participants were managers and directors only, the results presented are only tentative and of limited value for the purpose of generalisability. Furthermore, findings of this paper are limited to the KSA construction sector context only, as such, the level of generalisability outside this context may be very limited. Therefore, additional research is required to explore the complex issues of implementing KM strategies in other industry as well. This should lead to a generation of best practices in implementing KM strategies in the KSA.

\section{References}

Ahmad, H. and An, M (2008) Knowledge management implementation in construction projects: a KM model for Knowledge Creation, Collection and Updating, International Journal of Project Organisation and Management, Vol. 11, No. 2, pp. 133-166. 
Alavi, M. and Leidner, D. E. (2001) Knowledge management and knowledge management systems: conceptual foundations and research issues, MIS Quarterly, Vol. 25, No. 1, pp. 107136.

AL-Hussain, A. Z., Murphree Jr, E. L., and Bixler, C. H. (2012) Barriers to Knowledge Management in Saudi Arabia, Journal of Knowledge Globalization, Vol 5, No.1, pp. 47-75.

Alotaibi, F., Yusoff, R.Z. and R. Islam, (2013) Relationship between total quality management practices and contractors competitiveness, American Journal of Applied Sciences, Vol. 10, No. 3, pp. 247-252.

Bernard, H. R., (2006) Research methods in anthropology: Qualitative and quantitative approaches, Alta Mira Press, CA, USA.

Brooking, A. (1996) Intellectual capital - core asset for the third millennium enterprise, International Thompson Business Press, London.

Bryman, A. and Bell, E. (2015) Business Research Methods, Oxford University Press, London.

Burnett, S., Illingworth, L. and Webster, L., (2004) Knowledge Auditing and Mapping: A Pragmatic Approach, Knowledge and Process Management, Vol 11, No. 1, pp 25-37.

Calantone, R. J., Cavusgil, S. T., and Yushan, Z., (2002) Learning orientation, firm innovation capability, and firm performance, Industrial Marketing Management, Vol. 31, No. 6, pp. 515-524.

Carrillo, P., and Chinowsky, P., (2006) Exploiting knowledge management: the engineering and construction perspective, ASCE Management in Engineering, Vol. 22, No. 1, pp. 2-10.

Cohen, W. M. and Levinthal, D. A. (1990) Absorptive capacity: A new perspective on learning and innovation, Administrative Science Quarterly, Vol. 35, No. 1, pp. 128-152.

Creswell, J. W. (2014) Research Design: Qualitative, Quantitative, and Mixed Methods Approaches, Sage publishing, New York.

Dalkir, K. (2005) Knowledge management in theory and practice, Elsevier, Boston, MA.

Davenport, T. H., (1997) Information ecology, Oxford University Press, Oxford, UK.

Davenport, T. H., and Prusak, L. (1998) Working knowledge: How organizations manage what they know, Harvard Business School Press, Boston.

Dixon, N. M., (2000) Common knowledge: How companies thrive by sharing what they know, Harvard Business School Press, Boston, MA.

Egbu, C. O., and Robinson, H. S., (2005) Construction as a Knowledge-Based Industry, in Anumba, C. J., Egbu, C. O., and Carrillo, P. M., Knowledge Management in Construction, Blackwell Publishing, Oxford. 
Eppler, M. (2003) Making knowledge visible through knowledge maps: Concepts, elements, cases, in Handbook on Knowledge Management, Vol. 1 (Ed, Holsapple, C. W.), SpringerVerlag, Berlin.

Fakeeh, K. A., (2016) KSA 2030 Vision (Kingdom of Saudi Arabia's 2030 project) and its focus on families and students, International Journal of Computer Applications, Vol. 149, No. 1, pp. 46-48.

Fernie, S., Green, S.D. and Weller, R., (2003) Knowledge sharing Context, confusion and controversy, International Journal of Project Management, Vol. 21, No. 3, pp. 177-187.

Fraenkel, J. R. and Wallen, N. E. (2003) How to design and evaluate research in education, McGraw-Hill Companies Inc., New York, USA.

Gable, G. (1994) Integrating Case Study and Survey Research Methods: An Example in Information System, European Journal of Information Systems, Vol. 3, No. 2, pp.112-126.

Gerami, M., (2010) Knowledge Management, International Journal of Computer Science and Information Security, Vol. 7, No. 2, pp.234-238.

Hariharan, A., (2015) Knowledge management is fun, The Journal for Quality and Participation, Vol. 38, No. 2, pp. 34-38.

Hislop, D. (2013) Knowledge management in organisations: A critical introduction, Oxford University Press, UK.

Hyde, K.F., (2000) Recognising deductive processes in qualitative research, Qualitative Market Research: An International Journal, Vol. 3, No. 2, pp. 82-90.

Ipe, M. (2003) Knowledge sharing in organizations: A conceptual framework, Human Resource Development Review, Vol. 2, No. 4, pp. 337-359.

Kamara J., Anumba C. and Carrillo P.M. (2002) A CLEVER approach to selecting a knowledge management strategy, International journal of project management, Vol. 20, No. 3, pp. 205-211.

Kasimu MA, Roslan BA and Fadhlin A (2013) Knowledge sharing practices in construction organisation in Nigeria. International Journal of Engineering Research and Technology 2(1): $1-10$.

Khuzaimah, K. H., and Hassan, F. (2012) Uncovering tacit knowledge in construction industry: communities of practice approach, Procedia - Social and Behavioral Sciences, Vol. 50, No. 1, pp. $343-349$.

Liamputtong, P., and Ezzy, D., (2005) Qualitative research methods, Oxford University Press, South Melbourne.

Markus, M.L. (2001) Toward a theory of knowledge re-use: Types of knowledge re-use Situations and factors in re-use success, Journal of Management Information Systems, Vol. 18, No. 1, pp. 57-93.

Mayo, A., (1998) Memory bankers, People Management, Vol. 4, No. 2, pp. 34-38. 
McEvily, S. and Chakravarthy, B. (2002), The persistence of knowledge-based advantage: an empirical test for product performance and technological knowledge, Strategic Management Journal, Vol. 23, No. 4, pp. 285-305.

Nonaka, I., (1994) A dynamic theory of organisational knowledge creation, Organisational Science, Vol. 5, No. 1, 14-37.

Nonaka, I., and Takeuchi, H., (1995) The knowledge-creating company - How Japanese companies create the dynamics of innovation, Oxford University Press, London.

Noordin, M.F., Burhanuddin, L.A. and Kanaa, A., (2012) The current state of information management in the Malaysia Construction Industry, Australian Journal of Basic and Applied Sciences, Vol. 6, No. 6, pp. 138-145.

Olatokun, W., and Nwafor, C. I., (2012) The effect of extrinsic and intrinsic motivation on knowledge sharing intentions of civil servants in Ebonyi state, Nigeria, Information Development, Vol. 28, No. 3, pp. 216-234.

Patton, M. Q. (2014) Qualitative evaluation and research methods, Sage publications, Newbury Park, CA.

Rezgui, Y., Hopfe, C.J. and Vorakulpipat, C., (2010) Generation of knowledge management in the architecture, engineering and construction industry: An evolutionary perspective, Advanced Engineering Informatics, Vol. 24, No. 2, pp. 219-228.

RnR Market Research (2014) Saudi Arabia Construction Industry, Retrieved October 3, 2016, from www.prnewswire.com/news-releases/saudi-arabia-construction-industry-1098cagr-forecast-to-2018-285917141.html.

Senge, P. M., Lichtenstein, B. B., Kaeufer, K., Bradbury, H. and Carroll, J., S., (2007) Collaborating for systemic change, MIT Sloan Management Review, Vol. 48, No. 2, pp. 4453.

Shah, M. H., Rahneva, N., and Ahmed, R., (2014) Knowledge Management Practice at a Bulgarian Bank: A Case Study, International Journal of Knowledge Management (IJKM), Vol. 10, No. 3, pp. 54-69.

Singleton, R., and Straits, B. (2005) Approaches to social research, Oxford University Press, London.

Skyrme, D., (2001) Customers - A New Twist on Knowledge Management, Available from: http://www.skyrme.com/updates/u5.htm [Downloaded: 2016-02-18].

Smart, D.W., Stojanovic, T.A. and Warren, C.R. (2014) Is EIA part of the wind power planning problem?, Environmental Impact Assessment Review, Vol. 49, No. 1, pp. 3-23.

Stevens, R.H., Millage, J., and Clark, S., (2010) Waves of Knowledge Management: The Flow between Explicit and Tacit Knowledge, American Journal of Economics and Business Administration, Vol. 2, No. 1, pp. 129-135.

Suresh, S., and Egbu, C., (2012) Knowledge capture in small and medium enterprises: Construction Industry Perspective, LAP Lambert Academic Publishing, Germany. 
Suresh, S., Olayinka, R., Chinyio, E., and Renukappa, S., (2017) Impact of knowledge management practices on construction projects, Proceedings of the Institution of Civil Engineers - Management, Procurement and Law, Vol. 170, No. 1, pp. 27-43.

Szulanski, G. (2003), Sticky Knowledge - Barriers to Knowing in the Firm, Sage Publications Ltd, London.

Tan, H.C., Anumba, C.J., Carrillo, P.M., Bouchlaghem, D., Kamara, J., and Udeaja, C., (2010) Capture and Reuse of Project Knowledge in Construction, John Wiley and Sons, London.

Tashakkori, A. and Teddlie, C. (Eds.) (2010) Handbook of mixed methods in social and behavioral research, Sage publishing, Thousand Oaks, CA.

Teerajetgul, W., Chareonngam, C., and Wethyavivorn, P., (2009) Key knowledge factors in Thai construction practice, International Journal of project management, Vol. 27, No. 8, pp. 833-839.

Timetric (2014) Construction in Saudi Arabia - Key Trends and Opportunities to 2018, Retrieved March 30, 2016, from marketresearch.com.

Tutt, D, Pink, S, and Dainty, A., (2012) Ethnographic Research in the Construction Industry, Routledge, UK.

Ulrick, D. (1997) Organising around capabilities, In Hesselbein, F., Goldsmith, M., and Beckhard, R., (Eds), The organization of the future, Jossey-Bass publishing, San Francisco, USA.

Ventures (2015) KSA construction industry-capable of sustaining strong currents, Ventures Middle East LLC, Abu Dhabi, UAE.

Whittington, R., Pettigrew, A., Peck, S., Fenton, E., and Conyon, M., (1999) Change and complementarities in the new competitive landscape: A European panel study, Organization Science, Vol. 10, No. 5, pp. 583-600.

Whittom, A., and Roy, M. C., (2009) Considering participant motivation in knowledge management projects, Journal of Knowledge Management Practice, Vol. 10, No. 1, pp. 1-5.

Yu, Y., Hao, J., Dong. X. and Khalifa, M. (2013) A multilevel model for effects of social capital and knowledge sharing in knowledge-intensive work teams, International Journal of Information Management, Vol. 33, No. 5, pp. 780-790.

Zack, M. H., (2002) Developing a knowledge strategy: Epiogue, in the strategic management of intellectual capital and organisational knowledge - A collection of readings, Bontis, N., and Choo, C. W., (eds.), Oxford University Press, London. 